\title{
Reduction of Costs of Logistics for Chains of Pharmaceutical Products through the variation of the minimum value per order
}

\author{
Daniel Sarcos \\ University of California, United States of America \\ danielsarcos33@gmail.com
}

\begin{abstract}
Objectives: The Company under study is a leader in the mass consumer market, specifically in the production of pharmaceutical products based in France. It has developed all the organization necessary to get its products from the factories to the consumer, through the establishment of alliances with providers of logistics and sales services. Likewise, it uses a system of contracts with pharmacies, which establishes the commercial conditions and discounts that both parties must comply with. The company considers that this strategy presents a great complexity and difficulty given the differences between the categories. Therefore, the objective of this article is the design of strategies for the reduction of logistics costs of the company under study.

Methods/Statistical analysis: The process was divided into four (4) phases Diagnosis, analyse, proposals e implementation.

Findings: As a result, the minimum value per order (MOV) is diagnosed and the implications of the current commercial strategy are evaluated. Then the proposal to increase the MOV is developed, allowing a reduction in administrative costs and the reinvestment of these resources in the search for new clients.

Application/Improvements: This drives customers to make higher-value orders and therefore less orders a year, generating savings in the administrative expenses of the company studied. These proposals are evaluated and validated using historical sales records.
\end{abstract}

Keywords: Supply chain, business strategy. Minimum order value, logistics costs, pharmaceutical sector.

\section{INTRODUCTION}

Every commercial organization aims to produce, so from that it go aims to establish chains or business relationships that maximize their profits. To this end, market studies that demonstrate the specific situation of each sector, to thereby establish appropriate strategies should be made. In this sense, the pharmaceutical industry, offers a range of products that are of essential nature for humans, since they involve the strengthening or cure health client in this case is patient. So should view the levels of competitiveness of specific pharmaceutical organization to increase productivity by avoiding the fewest possible expenses.

\section{THEORETICAL FOUNDATION}

The company under study is one of the main producers and distributors of pharmaceutical products in the world, with presence in 44 countries, between this France. This in its continuous growth presents in the last years an increase in the complexity of its commercial operations, for which it is necessary to design and to develop applications within the information systems. In the same way, this generates an increase in operational costs ${ }^{1}$

The logistics team is continuously optimizing and improving its operations and processes in order to reduce transportation and administrative costs. The latter are the ones that have the greatest impact on the annual budget of the department since they always have the same value regardless of the volume or value of the order ${ }^{2}$

Within the pharmacy channel in France, there is a big difference between all customers, from large pharmacies in major cities, medium-sized in residential areas or small in agricultural villages. This generates a fairly large order volume range and the only existing restriction is the Minimum Order Value $(\mathrm{MOV})^{3}$ 
Because of this, the need to question the current model and procedures arises. The main approach is to find a method that will induce customers to spend less buying orders without generating a financial impact. Therefore, the present research proposes and implements strategies of handling the Minimum Value by Order that allow the company under study to reduce its costs, specifically those related to logistics and thus continue to drive the growth of trade.

\section{METHODOLOGY}

Knowing the operation of the commercial strategy and the commercial conditions, we proceed to design a model in which the Minimum Order Value (MOV) and other parameters are varied, which allows to pose different scenarios, then to evaluate them and to be able to consider the one that Is more in accordance with the objectives of the department. The following steps were followed for formulation ${ }^{4,5}$

- Definition of the objective and parameters.

- $\quad$ Building the model in Excel.

- Search for the historical date.

- Evaluation of the model through the variation of the parameters.

- Definition of the scenarios.

\section{RESULTS AND DISCUSSION}

Below is a SWOT analysis for the commercial strategy currently applied by the company under study.

\section{Analysis of the commercial strategy}

Strengths: The current commercial strategy is already known by customers and they carry out their annual sales planning based on their historical records and established commercial conditions. Similarly, sales representatives who know customers and seek to establish the markets that are most adapted to these and that allow them to achieve their sales goals in the most effective way.

Similarly, information systems already contain all the information about the markets, commercial conditions, customers, among others, and are configured to work under the scheme of the company under study. These systems take some time to establish and continually make improvements or changes that increase the fidelity and accuracy of them.

Weaknesses: given the number of categories and subcategories and the fact that each one has commercial conditions generates great complexity on the operations, specifically in the logistics department. There are many interrelated factors that need to be continuously monitored such as customer markets, trading conditions, discounts, promotions.

This strategy is highly dependent on information systems, specifically those used by the borrowers of the company under study. It would take a lot of human resources to be able to perform billing procedures manually. Another weakness is the low level of control and knowledge that the company has over the systems of the borrowers, in this case establishing a relationship of trust. In the event of a failure or error in the configuration of the commercial strategy, the company can suffer a great financial and reputation impact.

In the case of the arrival of a new category to the portfolio of products of the company, it is necessary to carry out the entire process of implementation and configuration of the systems, and then perform tests and verifications.

Opportunities: You can see certain opportunities for improvement in the business strategy that must be evaluated to determine the implications for the business and the channel. First is the variation of the MOV, which consists of increasing or decreasing this value to raise possible scenarios and estimate the impact.

Then a simplification of the commercial strategy is proposed, by means of the reduction or elimination of the markets and commercial conditions. In this sense, they are established from basic discounts, to which are added promotions based on the volume of units orders and on the total value of the order.

Threats: When implementing changes in the commercial strategy, customers can be very careful and 
there is a possibility that they will not accept the modifications. This can generate a serious financial impact on the company's sales.

Since the representatives know this situation with the customers, they also resist the changes, so that their performance is not affected.

Finally, the company is aware that the competition offers simpler commercial conditions and certain customers prefer to ally with these, to avoid the complexities of their commercial strategy.

\section{Proposals of commercial strategies}

Subsequently, proposals for variations in the MOV indicator

Variations in the MOV indicator

In meetings with logistics management, the proposal for variations of Minimum Order Value (MOV) is developed. It is proposed to observe the possible scenarios that can be obtained by increasing or decreasing this value. The main objective of this proposal is to seek savings in total billing costs by reducing the number of annual orders and alignment with business growth objectives. The two basic scenarios are the decrease or increase of this value $5,6,7,8,9,10,11,12,13,14$

In the case of a decrease, this allows the search for new small customers who do not have the capacity to make large orders. Although this generates a sales growth, a direct increase in costs is seen as the number of orders is increased, both new and old customers who prefer to make small orders to decrease their inventories in pharmacies. On the other hand, the profit margin is diminished.

In this sense, the scenario is considered to increase the MOV, which would force the clients to pass orders of greater volume and value. In this case, it is taking a push strategy so that customer inventories will be increased. Therefore, it is assumed that a reduction in purchase orders will occur. Likewise, the possible loss of business or impact to the profits of clients who do not want or can adapt to the increased MOV should be considered.

When a reduction occurs in the purchase orders, a saving in the total costs is generated directly. It is proposed to invest these resources to address new customers by offering them the possibility of placing purchase orders with a new customers MOV (MOV-NC). This will allow customers to know and evaluate the sales performance of the company's products under study, with the expectation that they will become regular customers. With this strategy it is possible to recover the impact to the profit and to generate incremental gains, therefore this one is aligned with the objectives of growth.

\section{Evaluation and Validation of proposals}

By varying the parameters of the models different scenarios can be presented using simulation in Excel for the distribution chain of pharmaceutical products under study. Only optimal results are shown at this stage.

From the company's information systems you can get detailed records of customer orders and invoices. For evaluations to be made, it is decided to work with historical sales data made in the year two thousand and thirteen (2013).

In order to evaluate the proposal of variation of the MOV, all the invoices are classified according to value ranges. With this data it is possible to determine the number of orders and the total invoiced that will be impacted when increasing the MOV.

For the analysis to be adapted to the year two thousand and fourteen (2014) that would be the possible moment of implementation of this proposal, it was considered a growth of five percent $(5 \%)$ in total invoices and eight percent (8\%) In the total invoiced. This growth corresponds to the growth that has been taking place in recent years in the pharmacy channel.

After different evaluations using the trial and error technique, it is concluded that the optimal value of the MOV should be four hundred euros $(400 €)$ and the MOV-NC of one hundred forty euros (140 €). The costs of billing and transportation are fixed and are considered four euros with forty five cents $(€ 4.45)$ and sixteen euros $(€ 16)$ respectively. Likewise, it is defined that new customers will have the possibility to 
make four (4) orders a year.

Table 1 presents the results of calculating the impact on income due to the increase in MOV. An impact of thirty percent $(30 \%)$, ten percent $(10 \%)$ and five percent $(5 \%)$ was generated for the value ranges from 0 to 200,200 to 300,300 to 400 euros. Respectively ${ }^{15,16,17,18,19,20,21}$.

Table 1. Impact calculation of income by establishing a MOV to $400 €$

\begin{tabular}{|c|c|c|c|c|}
\hline Rank & No. invoice & Income (euros) & \% impact & Impact (euros) \\
\hline $0-200$ & 8849 & 1531811.54 & 30 & 459543.46 \\
\hline $200-300$ & 8826 & 2.256 .67859 & 10 & 225667.86 \\
\hline $300-400$ & 6127 & 2198909.18 & 5 & 109945.46 \\
\hline \multicolumn{4}{|r}{ Total impact } \\
\hline
\end{tabular}

Table 2 shows that when the MOV is increased to four hundred euros ( $€ 400)$, a reduction of approximately forty-five percent $(45 \%)$ of purchase orders is made. This allows the company to save about forty-eight thousand euros $(€ 48,000)$ in billing expenses, which is the most critical budget for them. Significant savings are also made in transportation costs. Although precautions must be taken with the impact on income of about eight hundred thousand euros $(€ 800,000)$, which represents thirteen percent $(13 \%)$ of the income less than MOV.

These resources now available in the billing budget will be destined to the search of some two thousand seven hundred (2700) new pharmacies, through the possibility of ordering MOV-NC of one hundred forty euros (140€). In the most pessimistic case, in which all these orders are made to the MOV-NC, it is estimated that the income is one million five hundred thousand euros (1,500,000€). Considering the impact generated by the increase in the MOV, it gives the company the possibility to increase its revenues by seven hundred thousand euros $(€ 700,000)$.

Table 2. Results of the evaluation of the MOV variation model

\begin{tabular}{|l|l|}
\hline \multicolumn{2}{|c|}{ Historical } \\
\hline Orders $<$ MOV & 23802 \\
\hline Total costs Billed. Historical & $105.918,90 €$ \\
\hline Total costs transferred. Historical & $380.832,00 €$ \\
\hline \multicolumn{2}{|c|}{ Fixed parameters } \\
\hline Invoiced Cost / Order & $4,45 €$ \\
\hline Cost Transferred / Order & $16,00 €$ \\
\hline \multicolumn{2}{|c|}{ Variable Parameters } \\
\hline MOV & $400,00 €$ \\
\hline MOV new customers & $140,00 €$ \\
\hline Orders / Year New Customers & 4 \\
\hline
\end{tabular}

\begin{tabular}{|l|l|}
\hline \multicolumn{2}{|c|}{ Calculation } \\
\hline Entry $<$ MOV & $5.987 .399,31 €$ \\
\hline Impact on income & $795.156,78 €$ \\
\hline Total income & $5.192 .242,53 €$ \\
\hline Orders required & 12.981 \\
\hline Total cost invoice. & $57.763,70 €$ \\
\hline Total cost transferred. & $207.689,70 €$ \\
\hline Saving cost invoice. & $48.155,20 €$ \\
\hline Savings cost transferred. & $173.142,30 €$ \\
\hline New orders & 10821 \\
\hline New customers & 2705 \\
\hline New customer income & $1.514 .995,11 €$ \\
\hline Incremental revenue & $719.838,33 €$ \\
\hline
\end{tabular}

In Table $3 \mathrm{a}$ and $3 \mathrm{~b}$ the results obtained with defined discount rates are presented. Estimates used to determine which can be earned approximately four thousand five hundred $(4,500)$ purchase orders, representing a saving of some twenty thousand euros $(20,000 €)$. The marketing and sales department must locate a budget about seven hundred forty thousand euros $(€ 740,000)$. 
Table 3a. Evaluation invoice discount depending on the value range

\begin{tabular}{|c|c|c|c|}
\hline Ranges & $\begin{array}{c}\text { Discount rate } \\
\%\end{array}$ & $\begin{array}{c}\% \text { Reduction } \\
\text { in orders }\end{array}$ & $\begin{array}{c}\text { Order } \\
\text { less }\end{array}$ \\
\hline $150-500$ & 0 & 20 & 4978 \\
\hline $500-1000$ & 1 & 15 & 2411 \\
\hline $1000-2500$ & 1,5 & 5 & 570 \\
\hline $2500-5000$ & 2 & 2 & 52 \\
\hline $5000-$ máx & 2,5 & 0 & 0 \\
\hline
\end{tabular}

Table 3b. Evaluation invoice discount depending on the value range

\begin{tabular}{|c|c|c|c|c|}
\hline Ranges & $\begin{array}{c}\text { Entry } \\
\text { (Euros) }\end{array}$ & \# Order & Income undiscounted (Euros) & $\begin{array}{c}\text { Income } \\
\text { Discount } \\
\text { (Euros) }\end{array}$ \\
\hline & $1.452 .914,35$ & 19910 & $5.811 .657,40$ & $5.811 .657,40$ \\
\hline $500-1000$ & $1.709 .770,42$ & 15711 & $11.141 .613,42$ & $11.030 .197,29$ \\
\hline $1000-2500$ & $861.868,53$ & 11963 & $18.085 .272,49$ & $17.813 .993,40$ \\
\hline $2500-5000$ & $174.249,57$ & 2817 & $9.400 .097,52$ & $9.212 .095,57$ \\
\hline 5000-máx & - & 780 & $6.717 .485,71$ & $6.549 .548,57$ \\
\hline Won orders & 4553 & Total discount & \multicolumn{2}{|l|}{$738.634,31$} \\
\hline Cost / Order & 4,45 & & & \\
\hline Budget won & $20.259,17$ & & & \\
\hline
\end{tabular}

The marketing and sales department of the supplier company should place a budget close to seven hundred and forty thousand euros $(€ 740,000)$. This can be considered a great impact, but this discount comes associated with the simplification of trading strategies.

\section{CONCLUSIONS}

Increase the minimum value of the order (MOV), since this is very low and represents a strong impact on the budget of the logistics department. As shown in the results there is a great opportunity around this indicator.

The progressive implementation of the simplification of the commercial strategy. Changes in trading conditions should be made in the coming years. You can start with minor categories to carry out impact assessments.

In the case of the arrival of new categories, the commercial strategy must be aligned with the simplification proposal, in order to achieve a faster and more precise adaptation of the customer.

\section{REFERENCES}

[1]. Metzger, M., \& Donaire, V. Strategic Marketing Management. Mexico City, Mexico: International Thomson Publishing. 2007

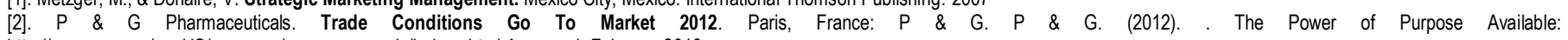
http://www.pg.com/en_US/company/purpose_people/index.shtml Accessed: February 2016

[3]. Sainz, JM. Commercial Distribution: Strategic Options. Madrid, Spain: ESIC Editorial. 2011

[4]. Schultz, \& Robinson, W. As direct the promotion of their sales. Barcelona, Spain: Ediciones Granica SA Soret, I. Madrid, Spain: ESIC Editorial. 2006

[5]. Holweg, M .; Disney, SM; Holmström, J .; Småros, J. Supply chain collaboration: making sense of the strategy continuum. European Management Journal, Vol. 23, no. 2. 2015. Pp. 170-181

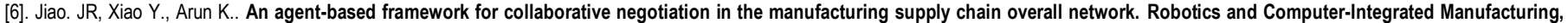
June (2). 2015. pp. 239-255

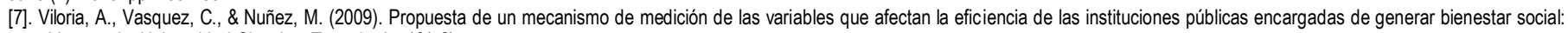
caso Venezuela. Universidad Ciencia y Tecnología, 13(52).

[8]. Viloria, A. (2007). Modelos socioeconómicos para las pymes. Universidad, Ciencia y Tecnología (UCT), 11(42), 39-44

[9]. Torres, M., Vasquez, C., \& Viloria, A. (2010). Gestión y calidad de la información en el gobierno electrónico. Universidad Ciencia y Tecnología, 14(54).

[10]. Viloria, A. (2012). INDICADORES DE GESTIÓN DE LOS PROGRAMAS DE MICROCRÉDITOS. REDIP-Revista Digital de Investigación y Postgrado, 1(3).

[11]. Amelec, V. (2015). Validation process container for distribution of articles for home. Advanced Science Letters, 21(5), 1413-1415.

[12]. Amelec, V. (2015). Validation of strategies to reduce exhausted shelf products in a pharmaceutical chain. Advanced Science Letters, 21(5), 1403-1405.

[13]. Amelec, V., \& Carmen, V. (2015). Design of a model of evaluation of productivity for microfinance institutions. Advanced Science Letters, 21(5), $1529-1533$.

[14]. Amelec, V., \& Carmen, V. (2015). Validation of a model for productivity evaluation for microfinance institutions. Advanced Science Letters, 21(5), 1610-1614.

[15]. Palencia-Fajardoa, O., Lis-Gutiérrezb, J. P., Gaitán-Anguloc, M., Ariza-Salazard, J., \& Viloriae, A. Competitiness of Clothing SMES in Neiva (Colombia). Small, 11, 50.

[16]. Amelec, V. (2015). Increased efficiency in a company of development of technological solutions in the areas commercial and of consultancy. Advanced Science Letters, 21(5), 1406-1408.

[17]. Amelec, V. (2015). Improvements in the Supply Chain of an Automotive Company Through the Implementation of Continuous Flow. Advanced Science Letters, 21(5), $1416-1418$.

[18]. Amelec, V. (2015). Methodology to increase the adaptability and flexibility of the supply chain of automotive company through lean manufacturing.Advanced Science Letters, 21(5), 1517-1520.

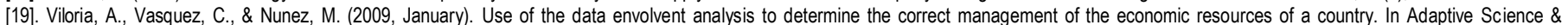
Technology, 2009. ICAST 2009. 2nd International Conference on (pp. 422-425). IEEE.

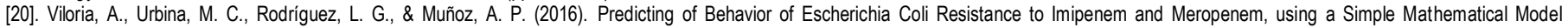

Regression. Indian Journal of Science and Technology, 9(46). 
[21]. Amelec, V., \& Alexander, P. (2015). Improvements in the Automatic Distribution Process of Finished Product for Pet Food Category in Multinational Company. Advanced Science Letters, 21(5), 14191421. 